\title{
Cardiac Device Set Screw Problem
}

National Cancer Institute

\section{Source}

National Cancer Institute. Cardiac Device Set Screw Problem. NCI Thesaurus. Code C99929.

The pacing and/or sensing problem associated with high impedance due to a poor connection between a lead and generator caused by a loose set screw. (ACC) 